\title{
Private information and business cycle risk sharing *
}

\author{
Alfred Duncan ${ }^{\dagger}$ \\ University of Cambridge
}

January 2016

\begin{abstract}
When individuals have private information about their own luck and income, the sharing of idiosyncratic risks is hampered by moral hazard. This friction also affects the optimal sharing of business cycle risks. Optimal allocations restrict the exposure of low wealth agents' consumption to business cycle risk. This encourages truth-telling by high wealth agents who have a high tolerance for business cycle risk, thereby increasing the extent to which idiosyncratic risks can be shared. Implementation of these optimal allocations requires restrictions in the trade of securities contingent on business cycle outcomes.
\end{abstract}

JEL Classification: D31, D52, D82.

Keywords: Incomplete markets, business cycles, distribution.

\footnotetext{
${ }^{*}$ I would like to thank Richard Dennis, Michael Hatcher, Charles Nolan and Jonathan Thomas for very helpful discussions and suggestions. All errors are my own.

${ }^{\dagger}$ Corresponding author. Email: a jmd $4 @ \mathrm{cam}$. ac.uk
} 


\section{INTRODUCTION}

This paper considers the interactions between idiosyncratic risk sharing and business cycle risk sharing in an environment where the outcomes of idiosyncratic risks are initially private information. The presence of business cycle risk can help constrained efficient mechanisms to identify individual agents' idiosyncratic risk outcomes. This increases the extent to which idiosyncratic risks can be shared.

The presence of idiosyncratic risk also affects the optimal sharing of business cycle risk. The optimal allocations depart from full consumption risk sharing with respect to the business cycle shock. Specifically, the optimal allocations restrict the exposure of low wealth agents to business cycle risk to such an extent that their consumption marginal rate of substitution across business cycle states is closer to unity than that of higher wealth agents. ${ }^{1}$ That wedge between respective marginal rates of substitution, capturing the interaction between idiosyncratic and business cycle risk sharing, is the key result of the paper and is presented as Proposition 2.

The intuition behind Proposition 2 is as follows: high wealth agents are more tolerant of business cycle risk than low wealth agents. ${ }^{2}$ Optimal mechanisms prevent low wealth individuals from accepting as much business cycle risk as they would prefer to accept in unrestricted trade. These optimal mechanisms deter high wealth agents from misrepresenting as low wealth agents, relaxing the incentive compatibility constraint. Consequently, optimal allocations permit some sharing of idiosyncratic risks even when these idiosyncratic risks are subject to private information.

The environment studied here is a two-period endowment economy, similar to those studied by Green and Oh (1991) and Kiyotaki (2010). The model can also be thought of as a two-period version of the model of Cole and Kocherlakota (2001).

\footnotetext{
${ }^{1}$ Under competitive trade in sequential one period state-contingent debt, consumption marginal rates of substitution across business cycle states are equated across high and low wealth agents (Proposition 5).

${ }^{2}$ This step requires the assumption of Decreasing Absolute Risk Aversion (DARA). Under DARA preferences, any increase in wealth will increase an agent's desired holdings of risky assets.
} 
Idiosyncratic risk is realised in the first period, while business cycle risk is realised in the second period. High endowment agents who report low income in the first period can use a hidden storage technology to delay consumption to the second period. Optimal mechanisms can identify misreporting high wealth agents by their demand for exposure to business cycle risk. In practise, the implementation of the optimal mechanisms described by Proposition 2 might include high effective marginal tax rates on high-risk savings products held by recipients of social insurance transfers. Alternatively, optimal allocations could potentially be implemented via the bundling of savings products by banks to restrict access to high-risk savings portfolios to clients with high declared net wealth. This paper is closely related to Green and Oh (1991), who study an environment where individuals' storage is assumed to be publicly observable and optimal mechanisms can identify misreporting high wealth agents from their high demand for storage. Green and Oh (1991) show that optimal mechanisms require deviations in intertemporal marginal rates of substitution across high and low wealth agents, a result that mirrors our finding of deviations in across-state marginal rates of substitution across high and low wealth agents.

The desire to make ex post interventions to the distribution of business cycle losses (bailouts) or to make interventions restricting the ex ante allocation of business cycle risk (macroprudential policy, broadly speaking) stems from concerns about the efficiency and/or fairness of market allocations of business cycle risk. This paper shows how sequential trade in business cycle risk securities can conflict with constrained efficient mechanisms of managing idiosyncratic risk. This result provides motivation for intervention in the market allocation of business cycle risk.

In describing a theory of bailouts and/or macroprudential policy, this paper is related to a growing literature describing the interactions between allocations of business cycle risk and business cycle volatility. To date, studies have focused on the interaction between optimal business cycle risk sharing and balance sheet externalities, or the interaction between business cycle risk sharing and aggregate demand externalities. Duncan and Nolan (2015) show in a generalised financial macroeco- 
nomics framework based on Bernanke, Gertler, and Gilchrist (1999) and Kiyotaki and Moore (1997) that when entrepreneurs or firm insiders are risk averse and firms' idiosyncratic risk cannot be passed on to outside investors, there is a conflict between the competitive allocation of business cycle risk and the constrained efficient allocations. Competitive allocations leave firms' balance sheets too exposed to business cycle risk, resulting in excessive volatility in leverage and resulting factor market wedges of inefficiency. ${ }^{3}$ Farhi and Werning (2013) study competitive equilibrium allocations of business cycle risk in an environment with New-Keynesian pricing rigidities. Competitive equilibrium allocations equate across-state consumption marginal rates of substitution across agents. Constrained efficient allocations depart from competitive allocations by favouring transfers toward agents who have a high demand for those goods whose prices exhibit high markups, reducing the welfare costs of wedges of inefficiency deriving from the price-setting friction.

Comparing the predictions of the model with the stylised facts of the behaviour of consumption inequality over the business cycle requires strict assumptions about preferences. During the Great Recession of 2007-09, P90-P10 ratio measures of inequality in consumption in the United States are documented to have fallen across a range of consumption measures (Fisher, Johnson, and Smeeding 2013; Meyer and Sullivan 2013; Perri and Steinberg 2012). This follows increases in consumption inequality prior to the Great Recession. Under the assumption of Constant Relative Risk Aversion (CRRA) across agents, these trends in consumption inequality deviate from full consumption insurance - there may be gains from trade available to both high and low wealth agents if low wealth agents were to absorb a greater share of consumption risk over the business cycle. This paper suggests that this type of deviation from full consumption risk insurance over the business cycle could be efficient, allowing more insurance of individual specific or firm specific risks than could be achieved if business cycle consumption risk were shared according to

\footnotetext{
${ }^{3}$ Duncan and Nolan (2015) can be thought of as a generalisation of the analyses of Carlstrom, Fuerst, and Paustian (2014), Krishnamurthy (2003) and Nikolov (2014) who consider specific financial macroeconomics models in which there is little or no conflict between the competitive and socially optimal allocations of business cycle risk.
} 
equation of variations in marginal utilities over the business cycle.

\section{THE MODEL}

A unit measure of ex ante identical agents live for two periods. Agents enjoy consumption with $c$ according to utility function $U(c)$, where $U$ is in the Decreasing Absolute Risk Aversion (DARA) class of preferences $\left(U^{\prime},-U^{\prime \prime}>0, A^{\prime}(c)<0\right.$, where $A(c)=-U^{\prime \prime}(c) / U^{\prime}(c)$ is the Arrow-Pratt measure of absolute risk aversion). The DARA class of preferences includes as a subset the class of utility functions exhibiting Constant Relative Risk Aversion (CRRA), where relative risk aversion is defined as $c A(c)$.

Consider an agent solving a portfolio choice problem with one risky and one safe asset. DARA preferences ensure that the agent's optimal holding of the risky asset increases in absolute terms as the agent's wealth increases. When business cycle risk is introduced in Section 4, constrained efficient mechanisms use these variations demand for exposure to business cycle risk to help identify misreporting high wealth agents.

Agents' discount second period instantaneous utility by factor $\beta$. In the first period, individual agents receive endowment $y_{l}$ with probability $\pi_{l}$ and $y_{h}$ with probability $\pi_{h}$, where $y_{l}<y_{h}$ and $\pi_{l}+\pi_{h}=1$. In period 2, all agents receive common endowment $z$, where $y_{l}<z<\pi_{l} y_{l}+\pi_{h} y_{h}$. That is, the second period endowment received by all agents is less than the expected first period endowment, but greater than the first period endowment received by low income agents. This assumption ensures positive gross savings. There exists a durable good, which converts the period 1 consumption good into the period 2 consumption good. First period savings $x$ return $R x$ units of the period 2 consumption good, where $R=1 / \beta$. Without loss of generality, the consumption enjoyed by an individual agent earning $y_{l}$ in period 1 is denoted $c_{1 l}$.

Within the class of problems we consider in this paper, the revelation principle holds. We can consider the constrained efficient allocations of any given problem 
to be attainable by a direct mechanism implemented by a benevolent social planner. The social planner aims to maximise the ex ante expected discounted utility of agents. There is no conflict between agents at time zero, before the idiosyncratic risk $y$ is drawn. The planner's objective function is

$$
\max _{\mathbf{c}, x} \pi_{l} U\left(c_{1 l}\right)+\pi_{h} U\left(c_{1 h}\right)+\beta\left[\pi_{l} U\left(c_{2 l}\right)+\pi_{h} U\left(c_{2 h}\right)\right]
$$

The planner's first and second period resource constraints are as follows and we attach Lagrange multipliers $\lambda_{1}, \lambda_{2}$ to them respectively:

$$
\begin{gathered}
\pi_{l} y_{l}+\pi_{h} y_{h} \geq \pi_{l} c_{1 l}+\pi_{h} c_{1 h}+x \\
z+R x \geq \pi_{l} c_{2 l}+\pi_{h} c_{2 h}
\end{gathered}
$$

The first period budget constraint (1.2) states that the sum of first period consumption across agents and savings (RHS) must be less than or equal to the total first period endowment income across agents (LHS). The second period budget constraint (1.3) states that total second period consumption (RHS) cannot exceed the sum of second period income and the gross return to first period savings (LHS). It is clear that in constrained efficiency requires that both resource constraints $(1.2,1.3)$ are binding. If either constraint were not binding, it must be the case that there is an individual agent whose consumption could be increased without violation of any of the constraints faced by the social planner.

\section{PERFECT INFORMATION}

With perfect information, the planner solves (1.1) subject to the resource constraints $(1.2,1.3)$. The first order necessary conditions can be written as follows

$$
\begin{array}{ll}
c_{1 i}: & \lambda_{1}=U^{\prime}\left(c_{1 l}\right)=U^{\prime}\left(c_{1 h}\right) \\
c_{2 i}: & \lambda_{2} / \beta=U^{\prime}\left(c_{2 l}\right)=U^{\prime}\left(c_{2 h}\right)
\end{array}
$$




$$
x: \quad \lambda_{1}=R \lambda_{2}
$$

From the first order necessary conditions, we can see that under the planner's solution, agents enjoy full consumption insurance, with consumption equated across high and low income agents. Agents also enjoy perfect consumption smoothing, with

$$
c_{1 l}=c_{1 h}=c_{2 l}=c_{2 h}=\frac{1}{1+\beta}\left[\pi_{l} y_{l}+\pi_{h} y_{h}+\beta z\right] .
$$

This solution characterises the first-best efficient allocations in our model. The incomes of high endowment and low endowment agents are shared, as though all agents hold equity shares in each others' incomes. The storage technology is used to smooth the consumption of all households over the two periods.

\section{PRIVATE INFORMATION}

Now, consider the same model, but where the planner cannot directly observe which agents have received the high endowments, and which have received the low endowments. It is also assumed that individuals savings held in the durable good cannot be observed by the planner. ${ }^{4}$ Agents now have the option of lying about their endowment to the planner, and saving any excess income they do not wish to consume in the first period, earning return $R$ on all savings. The revelation principle holds in our environment, and optimal allocations can be implemented by the planner, whose problem is now subject to the following truth-telling constraint to which we attach the Lagrange multiplier $\mu$ :

$$
U\left(c_{1 h}\right)+\beta U\left(c_{2 h}\right)=V\left(c_{1 l}+y_{h}-y_{l}, c_{2 l}\right) .
$$

\footnotetext{
${ }^{4}$ The assumption that storage is hidden is important. When storage is observable, misreporting high type agents are unable to smooth consumption. This inability to smooth consumption can be manipulated by the social planner to provide some consumption insurance across high and low type agents that is not possible when storage is hidden. See Green and Oh (1991) and Kiyotaki (2010) for details.
} 
The value function $V$ represents the expected discounted utility obtainable by an agent who receives a high endowment and fraudulently declares a low endowment. In the first period, they recieve a transfer from the planner equal to $c_{1 l}-y_{l}$, which is added to their true endowment of $y_{h}$. In the second period they receive transfer $c_{2 l}-z$, which they can add to their endowment $z$ and the gross return from any private savings in the durable good.

It is clear to see that any similar constraint to ensure truth-telling from agents receiving a low endowment would not be binding under any optimal consumption plan. The primary objective of the planner is to provide insurance to agents receiving low endowments, and it is always in the interest of those agents to declare their endowments truthfully.

We now solve for the value attainable by a recipient of a high endowment who misreports their endowment before returning to the planner's problem.

\subsection{The VAlue OF MisRePORTING}

Consider a recipient of a high endowment who reports a low endowment. We denote their consumption allocations in periods 1 and 2 by $\hat{c}_{1}$ and $\hat{c}_{2}$ respectively. As storage is hidden, this agent can use the storage technology to smooth consumption across the two periods. The misreporting agent solves the following problem

$$
V\left(c_{1 l}+y_{h}-y_{l}, c_{2 l}\right)=\max _{\hat{\mathbf{c}}, x} U\left(\hat{c}_{1}\right)+\beta U\left(\hat{c}_{2}\right)
$$

subject to the resource constraints

$$
\begin{gathered}
c_{1 l}+y_{h}-y_{l} \geq \hat{c}_{1}+\hat{x}, \\
R \hat{x}+c_{2 l} \geq \hat{c}_{2} .
\end{gathered}
$$

The left hand side of the first resource constraint adds the difference between high and low endowments (the hidden part of the endowment) to the consumption allocation of a truth-telling low endowment agent. The left hand side of the second 
resource constraint adds the gross return of any hidden savings to the consumption allocation of a truth-telling low endowment agent. The solution to this problem is

$$
\begin{gathered}
\hat{c_{1}}=\hat{c_{2}}=\frac{1}{1+\beta}\left[c_{1 l}+y_{h}-y_{l}+\beta c_{2 l}\right] \\
V\left(c_{1 l}+y_{h}-y_{l}, c_{2 l}\right)=(1+\beta) U\left(\frac{1}{1+\beta}\left[c_{1 l}+y_{h}-y_{l}+\beta c_{2 l}\right]\right)
\end{gathered}
$$

\subsection{THE PLANNER'S SOLUTION}

The planner maximises (1.1) subject to the resource constraints $(1.2,1.3)$ and the truth-telling constraint (3.1) with the solution (3.2). The first order necessary conditions are

$$
\begin{aligned}
c_{1 l}: & \pi_{l} \lambda_{1}=\pi_{l} U^{\prime}\left(c_{1 l}\right)-\mu U^{\prime}\left(\frac{1}{1+\beta}\left[c_{1 l}+y_{h}-y_{l}+\beta c_{2 l}\right]\right) \\
c_{2 l}: & \pi_{l} \lambda_{2}=\pi_{l} \beta U^{\prime}\left(c_{2 l}\right)-\mu \beta U^{\prime}\left(\frac{1}{1+\beta}\left[c_{1 l}+y_{h}-y_{l}+\beta c_{2 l}\right]\right) \\
c_{1 h}: & \pi_{h} \lambda_{1}=\pi_{h} U^{\prime}\left(c_{1 h}\right)+\mu U^{\prime}\left(c_{1 h}\right) \\
c_{2 h}: & \pi_{h} \lambda_{2}=\pi_{h} \beta U^{\prime}\left(c_{2 h}\right)+\mu \beta U^{\prime}\left(c_{2 h}\right) \\
x: & \lambda_{1}=R \lambda_{2}
\end{aligned}
$$

It is straightforward to verify that the solution to this problem is

$$
c_{1 l}=c_{2 l}=\frac{1}{1+\beta}\left[y_{l}+\beta z\right], \quad c_{1 h}=c_{2 h}=\frac{1}{1+\beta}\left[y_{h}+\beta z\right] .
$$

\subsection{COMPETITIVE EQUILIBRIUM WITH NON-CONTINGENT DEBT}

The solution described by Equation 3.3 is consistent with consumption smoothing over time by individual agents $\left(\beta U^{\prime}\left(c_{2 l}\right) / U^{\prime}\left(c_{1 l}\right)=1 / R\right)$, which under our specific restrictions on parameter values (notably $\beta=1 / R$ ) means that individual consumption paths are constant across time $\left(c_{1 j}=c_{2 j}\right)$. But the solution also restricts the 
total present value of consumption of each agent to be equal to the present value of their endowment paths $\left(c_{1 l}+\beta c_{2 l}=y_{l}+\beta z\right)$. This indicates that there is no sharing of the idiosyncratic endowment shocks across agents. There is no redistribution of present value wealth after endowments are realised in period 1.

Proposition 1 shows that these constrained optimal allocations described in (3.3) can be implemented through decentralised trade in one period non-contingent loans, where this loan market opens after endowments have been realised in period 1 . These loan markets enable agents to bring forward or delay consumption from and to the future, which offers an improvement in welfare terms relative to autarky, but little insurance against endowment risks.

Proposition 1. When aggregate income is constant, the constrained efficient allocations under private information with hidden storage can be implemented with decentralised trade in non-contingent one period debt contracts.

The proof of Proposition 1 is contained in Appendix A.

\section{BUSINESS CYCLE RISK}

Now we introduce business cycle risk through an aggregate endowment shock in period 2. The common endowment received in period 2, $z$, can take the values $z_{L}<z_{H}$, with probabilities $P\left(z_{L}\right), P\left(z_{H}\right)$ respectively, where $P\left(z_{L}\right)+P\left(z_{H}\right)=1$.

What we're interested in is how the aggregate risk $z$ is shared, and whether decentralised trade in the simple debt contracts we considered in the previous section can still implement constrained efficient allocations. We start by describing the planner's problem and the planner's first order necessary conditions before considering whether these conditions can be satisfied by decentralised sequential trade in non-contingent or aggregate state-contingent debt securities. Then we return to solve the planner's problem and derive the intuition behind our result that decentralised trade in these simple contracts cannot implement constrained efficient allocations. 


\subsection{THE PLANNER'S PROBLEM}

When the economy suffers from business cycle risk, the planner's objective function takes expectations of individual utilities across individual agents and aggregate states (z). The planner's objective function can be written as follows,

$$
\max _{\mathbf{c}, x} \pi_{l} U\left(c_{1 l}\right)+\pi_{h} U\left(c_{1 h}\right)+\beta \mathbb{E}_{z}\left[\pi_{1} U\left(c_{2 l}(z)\right)+\pi_{h} U\left(c_{2 h}(z)\right)\right],
$$

subject to the budget constraints,

$$
\begin{gathered}
\pi_{l} y_{l}+\pi_{h} y_{h} \geq \pi_{l} c_{1 l}+\pi_{h} c_{1 h}+x, \quad\left(\lambda_{1}\right) \\
R x+z \geq \pi_{l} c_{2 l}(z)+\pi_{h} c_{2 h}(z) \quad z \in\left\{z_{L}, z_{H}\right\} . \quad\left(\lambda_{2}(z)\right)
\end{gathered}
$$

The first period budget constraint is the same as in the earlier cases with no business cycle risk. The second period budget constraints are contingent on the realisation of the common shock $(z)$.

The incentive compatibility constraints also change. Agents report their endowments following realisation in period 1 . Therefore, when deciding whether or not to report truthfully, they must take expectations over the allocation policy rule $\left(c_{2 l}(z)\right)$ and the distribution of common shocks $(z)$. The first incentive compatibility constraint is

$$
U\left(c_{1 h}\right)+\beta \mathbb{E} U\left(c_{2 h}(z)\right) \geq V\left(c_{1 l}+y_{h}-y_{l}, c_{2 l}(z)\right), \quad(\mu)
$$

where $V\left(c_{1 l}+y_{h}-y_{l}, c_{2 l}(z)\right)$ describes the value obtainable to a an agent who receives a high endowment in the first period but declares a low income to the social planner.

\subsubsection{KEY FEATURES OF CONSTRAINED EFFICIENT ALLOCATIONS}

Derivations of the equations in this section are contained in Appendix B.

A useful object that we will be relying on to compare allocations is the con- 
sumption marginal rate of substitution between high and low realisations of the business cycle shock, $z$.

Definition 1. The across-state consumption marginal rate of substitution of individual agent $i$ is defined as follows:

$$
\frac{U^{\prime}\left(c_{2 i}\left(z_{H}\right)\right)}{U^{\prime}\left(c_{2 i}\left(z_{L}\right)\right)} .
$$

For all of the allocations we consider, the across-state consumption marginal rate of substitution will be between zero and one, with $\frac{U^{\prime}\left(c_{2 i}\left(z_{H}\right)\right)}{U^{\prime}\left(c_{2 i}\left(z_{L}\right)\right)}=1$ corresponding to the situation where agent $i$ 's consumption is independent of the realisation of $z$, and with $\frac{U^{\prime}\left(c_{2 i}\left(z_{H}\right)\right)}{U^{\prime}\left(c_{2 i}\left(z_{L}\right)\right)}<1$ corresponding to situations where the period 2 consumption of agent $i$ is greater upon the realisation of the boom, $z=z_{H}$, than upon the realisation of the recession, $z=z_{L}$.

Misreporting agents receive the same transfer from the planner in period 2 as truth-telling low type agents. However, bringing forward any savings from the previous period leaves them with greater expected consumption. Under the assumption of DARA preferences, the across-state consumption marginal rate of substitution for misreporting agents is strictly less than that of truth-telling low reporting agents:

$$
\frac{U^{\prime}\left(\hat{c}_{2}\left(z_{H}\right)\right)}{U^{\prime}\left(\hat{c}_{2}\left(z_{L}\right)\right)}>\frac{U^{\prime}\left(c_{2 l}\left(z_{H}\right)\right)}{U^{\prime}\left(c_{2 l}\left(z_{L}\right)\right)} .
$$

The planner can use this difference in consumption marginal rates of substitution to attain greater insurance against idiosyncratic risks while retaining truth-telling: A small perturbation in consumption allocations that reduces the absolute difference in period two low type consumption allocations $\left|c_{2 l}\left(z_{H}\right)-c_{2 l}\left(z_{L}\right)\right|$ offers a relatively large welfare gain to truth-telling low types, at the incentive cost of a relatively small welfare gain to misreporting agents. In incentive terms, it is best to insure ex ante idiosyncratic risks through access to business cycle risk insurance, rather than through expected consumption.

This result is summarised by Proposition 2. Constrained efficient allocations 
restrict the volatility of low endowment agents' consumption in response to business cycle risk to such an extent that these agents' across-state consumption marginal rate of substitution is greater than that of high endowment agents.

Proposition 2. When agents' preferences exhibit DARA, then under the constrained efficient allocations, the period 2 across-state consumption marginal rate of substitution of low wealth agents is greater than that of high endowment agents:

$$
\frac{U^{\prime}\left(c_{2 l}\left(z_{H}\right)\right)}{U^{\prime}\left(c_{2 l}\left(z_{L}\right)\right)}>\frac{U^{\prime}\left(c_{2 h}\left(z_{H}\right)\right)}{U^{\prime}\left(c_{2 h}\left(z_{L}\right)\right)} .
$$

A proof of Proposition 2 is contained in Appendix B.

Allocations consistent with Proposition 2 cannot be implemented via mechanisms that allow for unrestricted trade in business cycle risk insurance before the realisation of the common shock in period 2. The inequality described by 4.2 shows that if these markets were to open, there would be gains from trade available from the sale of exposure to business cycle risk from the high endowment agents to the low endowment agents. Unfortunately, this ex post trade would increase the value attainable by agents who misreported their income ex ante, and the mechanism would no longer be incentive compatible. Whether through a direct mechanism with tax or regulatory restrictions on business cycle risk contracts, or through a decentralised mechanism with voluntary restrictions on trade in business cycle risk contracts, constrained efficient mechanisms must somehow restrict trade in business cycle risk contracts.

It is also important to note that as misreporting agents have access to the private storage technology, their ex ante intertemporal marginal rates of substitution bind at the rate of return offered by the storage technology, and are unaffected by small perturbations in consumption allocations around the constrained efficient solution. It follows that constrained efficient allocations are consistent with high and low type agents' ex ante intertemporal marginal rates of substitution equating to the rate of 
return to the storage technology.

$$
\frac{\mathbb{E}_{z} \beta U^{\prime}\left(c_{2 i}(z)\right)}{U^{\prime}\left(c_{1 i}\right)}=\frac{1}{R}
$$

One corollary of this result is that the constrained efficient allocations can be implemented via a mechanism that allows for unrestricted side trading in non-contingent debt contracts.

\subsection{COMPETITIVE EQUILIBRIUM WITH NON-CONTINGENT DEBT}

In period 1, upon realisaton of endowments, individual agent in receipt of endowment $y_{i}$ can buy (+) or offer (-) unlimited quantities of non-contingent debt $b_{i}$, each unit of which returns one unit of the consumption good in the second period. The agent's problem can be written as follows:

$$
\max _{\mathbf{c}_{i}, x_{i}, b_{i}} U\left(c_{1 i}\right)+\beta U\left(c_{2 i}\right)
$$

subject to the resource constraints

$$
\begin{gathered}
y_{i} \geq c_{1 i}+x_{i}+Q b_{i}, \quad\left(\lambda_{1 i}\right) \\
R x_{i}+b_{i}+z \geq c_{2 i}(z) . \quad\left(\lambda_{2 i}(z)\right)
\end{gathered}
$$

In symmetric equilibrium, the total supply of one period bonds must be equal to zero:

$$
\pi_{l} b_{l}+\pi_{h} b_{h}=0 .
$$


The first order necessary conditions are

$$
\begin{aligned}
c_{1 i}: & \lambda_{1 i}=U^{\prime}\left(c_{1 i}\right) \\
c_{2 i}: & \lambda_{2 i}=\beta U^{\prime}\left(c_{2 i}(z)\right) \\
x: & \lambda_{1 i}=R \mathbb{E} \lambda_{2 i}(z) \\
b: & Q \lambda_{1 i}=\mathbb{E} \lambda_{2 i}(z)
\end{aligned}
$$

The problem with the non-contingent debt contracts is that while they do provide some intertemporal insurance in the form of consumption smoothing, they do not provide sufficient insurance against business cycle risks. Creditors (receivers of high endowments) and debtors (low endowments) face identical absolute consumption risks in the second period with respect to the business cycle risk. But debtors have higher expected marginal utility in the second period than debtors, and any absolute decrease in consumption results in a greater proportional increase in marginal utility than that suffered by a creditor following the identical absolute change in consumption (under DARA preferences).

Proposition 3. With business cycle risk present and DARA preferences, and with trade in non-contingent debt contracts only, the period 2 across-state consumption marginal rate of substitution of low wealth agents is less than that of high endowment agents:

$$
\frac{U^{\prime}\left(c_{2 l}\left(z_{H}\right)\right)}{U^{\prime}\left(c_{2 l}\left(z_{L}\right)\right)}<\frac{U^{\prime}\left(c_{2 h}\left(z_{H}\right)\right)}{U^{\prime}\left(c_{2 h}\left(z_{L}\right)\right)} .
$$

The proof of Proposition 3 is contained in Appendix C.

Corollary 4. With business cycle risk present and under DARA preferences, the competitive equilibrium with sequential trade in non-contingent debt only is not constrained efficient.

Proof. The proof of Corollary 6 follows directly from consideration of equation 4.4, which contradicts equation 4.2. 
It is this difference in how each group's marginal utilities respond to the business cycle risk that indicates that a market for business cycle risk insurance, or an allocation mechanism replicating the missing business cycle risk insurance could yield a Pareto welfare gain. Low endowment agents have a relatively low acrossstate marginal rate of substitution compared with high endowment agents. It follows that if a market in business cycle risk insurance were to open before the realisation of the business cycle risk $z$, gains from trade would be possible from trade in this market, with low endowment agents purchasing business cycle risk insurance from high endowment agents.

Now, we introduce a market for business cycle risk insurance into our competitive environment.

\subsection{THE COMPETITIVE EQUILIBRIUM WITH STATE-CONTINGENT DEBT CON- TRACTS}

We've shown that simple non-contingent debt contracts cannot implement constrained efficient allocations when our endowment economy suffers from aggregate or business cycle risk. Ex ante, all individual agents are identical, but after the realisation of idiosyncratic risk, some agents have greater wealth and consumption than others. These low wealth individuals are less able and willing to bear business cycle risk than the higher wealth individuals. Since the outcome of the business cycle risk is common knowledge, the planner is able to construct a superior mechanism that does provide low wealth agents with some insurance against the business cycle risk shock, resulting in a Pareto welfare improvement.

In this section, we consider whether decentralised trade could achieve constrained efficient allocations, if individual agents were able to trade a richer set of securities that allowed for payoffs that respond to the outcome of the business cycle risk.

In period 1, upon realisaton of endowments, individual agent in receipt of endowment $y_{i}$ can buy (+) or offer (-) unlimited quantities of state-contingent debt $b_{i}\left(z^{\prime}\right)$, each unit of which returns one unit of the consumption good in the second 
period if and only if the realisation of $z$ is $z=z^{\prime}$. Each security $b\left(z^{\prime}\right)$ trades at price $Q\left(z^{\prime}\right)$ in period 1 .

The agent's problem can be written as follows:

$$
\max _{\mathbf{c}_{i}, x_{i}, b_{i}} U\left(c_{1 i}\right)+\beta U\left(c_{2 i}\right)
$$

subject to the resource constraints

$$
\begin{gathered}
y_{i} \geq c_{1 i}+x_{i}+Q(z) b_{i}(z), \quad\left(\lambda_{1 i}\right) \\
R x_{i}+b_{i}(z)+z \geq c_{2 i}(z) . \quad\left(\lambda_{2 i}(z)\right)
\end{gathered}
$$

In symmetric equilibrium, the total supply of bonds contingent on state $z$ must be equal to zero:

$$
\pi_{l} b_{l}(z)+\pi_{h} b_{h}(z)=0 \quad \forall z
$$

The first order necessary conditions are

$$
\begin{aligned}
c_{1 i}: & \lambda_{1 i}=U^{\prime}\left(c_{1 i}\right) \\
c_{2 i}: & \lambda_{2 i}=\beta U^{\prime}\left(c_{2 i}(z)\right) \\
x: & \lambda_{1 i}=R \mathbb{E} \lambda_{2 i}(z) \\
b(z): & Q(z) \lambda_{1 i}=\lambda_{2 i}(z) \quad \forall z
\end{aligned}
$$

We can see straight away that the agents in our economy do in fact utilise the statecontingent contracts. There is full consumption risk sharing with respect to the business cycle risk, $z$ :

Proposition 5. With trade in both non-contingent debt and one period securities contingent on the aggregate shock $z$, the period 2 across-state consumption marginal rate of substitution of low wealth agents is equal than that of high endowment agents:

$$
\frac{U^{\prime}\left(c_{2 l}\left(z_{H}\right)\right)}{U^{\prime}\left(c_{2 l}\left(z_{L}\right)\right)}=\frac{U^{\prime}\left(c_{2 h}\left(z_{H}\right)\right)}{U^{\prime}\left(c_{2 h}\left(z_{L}\right)\right)} .
$$


Proof. From the agents' first order necessary condition for borrowing $b(z)$, we have $\lambda_{2 l}\left(z_{H}\right) / \lambda_{2 l}\left(z_{L}\right)=\lambda_{2 h}\left(z_{H}\right) / \lambda_{2 h}\left(z_{L}\right)=Q\left(z_{H}\right) / Q\left(z_{L}\right)$. From here, we can make the substitution $\lambda_{2 i}=\beta U^{\prime}\left(c_{2 i}(z)\right)$ to complete the proof.

Corollary 6. With business cycle risk present, the competitive equilibrium with sequential trade in non-contingent debt and aggregate risk insurance securities is not constrained efficient.

Proof. The proof of Corollary 6 follows directly from consideration of equation 4.5, which contradicts equation 4.2.

When business cycle risk markets are open, and loan contracts can be written to be contingent on the aggregate state, there is full consumption insurance. High income and low income agents experience the same variation in marginal utilities across aggregate states.

\section{NUMERICAL EXAMPLE}

Table 5.1 presents the results of numerical simulations of the model with constrained efficient allocations (Section 4.1), non-contingent debt contracts (Section 4.2) and aggregate state contingent debt contracts (Section 4.3). The idiosyncratic risk state space has been extended from a high-low shock $\left(y \in\left\{y_{l}, y_{h}\right\}\right)$ to a vector of ten possible realisations $\left(y \in\left\{y_{1}, y_{2}, \ldots, y_{10}\right\}\right)$. Otherwise, the model is identical to earlier sections.

Period 1 endowments are drawn as follows: $y_{i}=5+(i-1) / 9$ and endowments are drawn from a binomial distribution $B(9,0.5)$. That is, $y_{i}$ is drawn with probability $\pi_{i}=\left(\begin{array}{c}9 \\ i-1\end{array}\right)\left(\frac{1}{2}\right)^{9}$. The common period 2 endowment $z$ is $z_{L}=4$ with probability $P\left(z_{L}\right)=1 / 2$, and $z_{H}=5$ otherwise. Agents enjoy consumption according to $U(c)=\sqrt{c}$. Agents discount second period expected utility according to factor $\beta=0.95$, and the storage technology provides gross return $R=1 / \beta$.

Table 1(e) exhibits the across-state consumption marginal rates of substitution, defined as $\frac{U^{\prime}\left(c_{2}\left(y, z_{H}\right)\right)}{U^{\prime}\left(c_{2}\left(y, z_{L}\right)\right)}$. Consistent with equations 4.2, 4.4 and 4.5, the across-state 

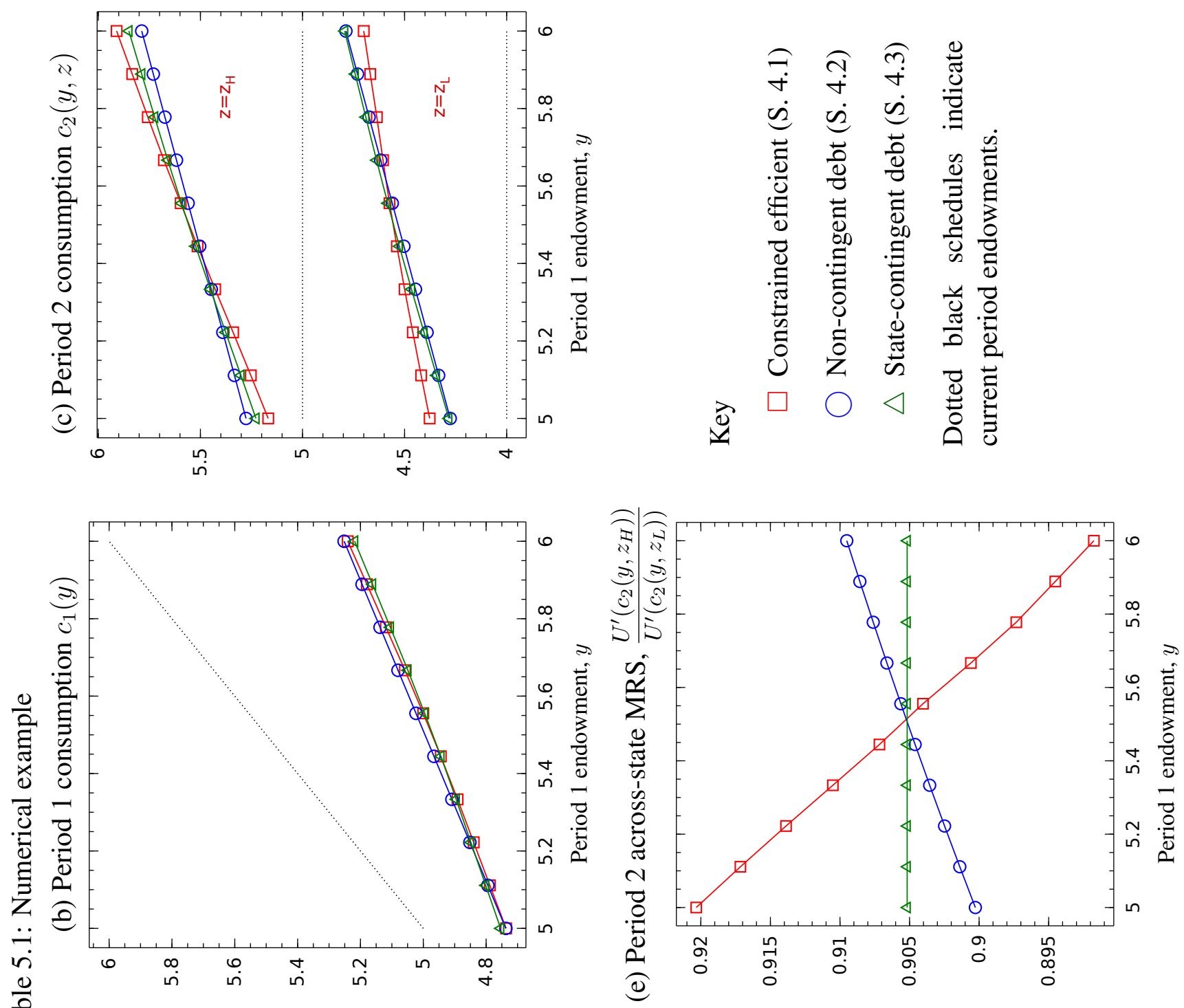

$\frac{0}{\pi}$
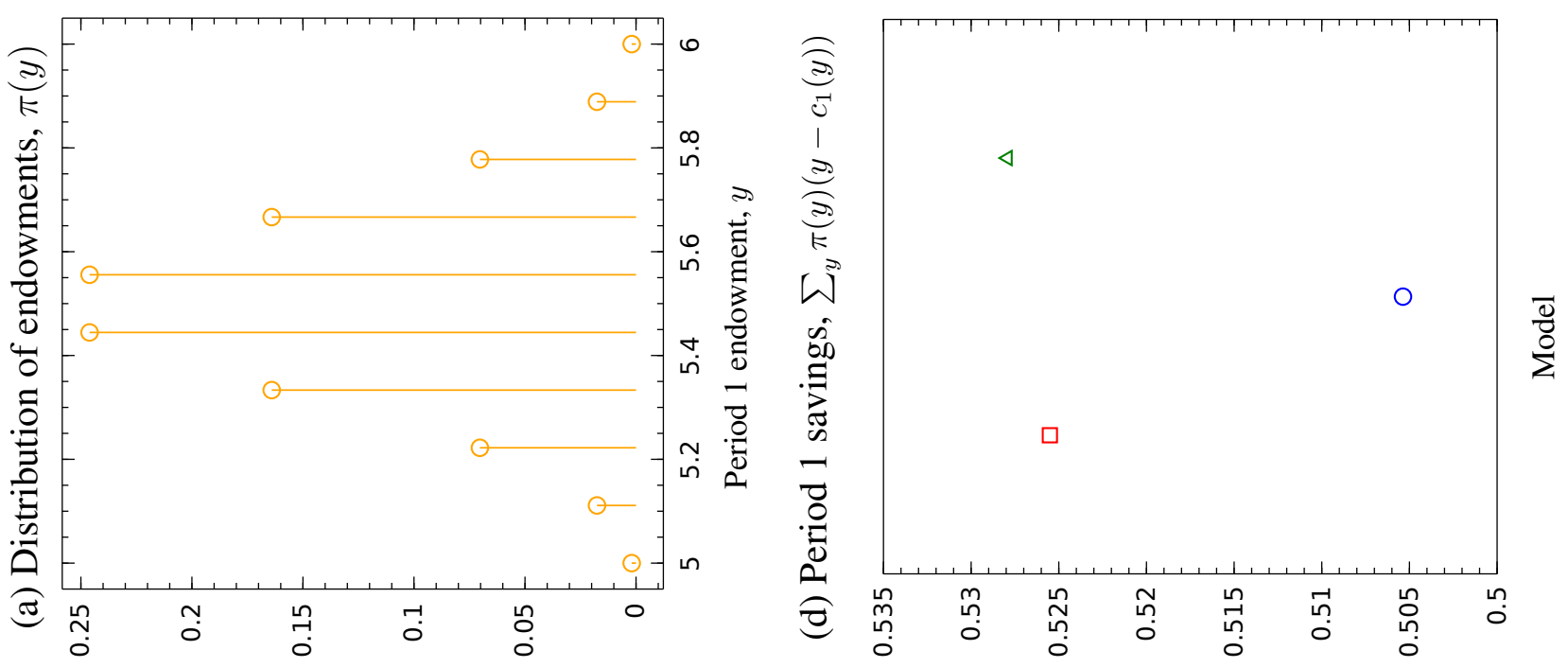
consumption MRS is decreasing in initial endowments under the constrained efficient allocations, increasing under non-contingent debt, and constant under statecontingent debt. This pattern is also shown in panel (c), which plots period 2 consumption allocations. Under the constrained efficient allocations, the sensitivity of period 2 consumption to period 1 endowments is low (high) when the common shock is low (high). In other words, the distribution of consumption across agents widens in the boom state and tightens in the recession state.

Total period 1 savings are low when the contract space is restricted to noncontingent debt (panels $b$ and $d$ ). The intuition behind the increase in savings under the constrained efficient and contingent debt allocations is that these mechanisms enable the economy to mobilise the savings of high wealth agents. When the contract space is restricted to non-contingent debt only, these high wealth agents have little motive for precautionary savings. When business cycle risk markets are open, higher endowment agents can use these markets to increase their exposure to business cycle risk in return for higher second period consumption. At the same time, low endowment agents can insure their business cycle risk for a small reduction in expected consumption.

\section{Discussion}

Under the optimal allocations studied here and characterised by Proposition 2, business cycle risk allocations depart from full risk sharing in the sense that more wealthy agents experience wilder swings in expected marginal utility over the business cycle than low wealth agents. The problem of efficiently sharing the burden of the business cycle over the population conflicts with the problem of idiosyncratic risk sharing either through social insurance or private risk sharing arrangements.

The optimal allocations derived in this paper could be achieved either through long term private contracts, or through state intervention with taxation, transfers and financial regulation instruments. The important challenge faced by either competitive or social mechanisms aimed at implementing allocations consistent with 
optimality in our environment is whether or not these mechanisms can effectively deter, tax or eliminate side-trades in securities contingent on business cycle risk between individual pairs of agents. These side-trades if permitted would result in the equating of across-state marginal rates of substitution, tightening the incentive compatibility constraint with respect to the reporting of individual specific risk outcomes. 


\section{REFERENCES}

Ben S. Bernanke, Mark L. Gertler, and Simon Gilchrist. The financial accelerator in a quantitative business cycle framework. In J. B. Taylor and M. Woodford, editors, Handbook of Macroeconomics, volume 1, Part C, chapter 21, pages 1341-1393. Elsevier, 1 edition, 1999.

Charles T. Carlstrom, Timothy S. Fuerst, and Matthius Paustian. Optimal Contracts, Aggregate Risk, and the Financial Accelerator. Working Paper 1420, Federal Reserve Bank of Cleveland, October 2014.

Lawrence Christiano and Daisuke Ikeda. Government Policy, Credit Markets and Economic Activity. NBER Working Papers 17142, National Bureau of Economic Research, Inc, June 2011.

Harold L Cole and Narayana R Kocherlakota. Efficient Allocations with Hidden Income and Hidden Storage. Review of Economic Studies, 68(3):523-42, July 2001 .

Alfred Duncan and Charles Nolan. Systemic Risk Markets and the Financial Accelerator. Working paper, November 2015.

Emmanuel Farhi and Ivan Werning. A Theory of Macroprudential Policies in the Presence of Nominal Rigidities. NBER Working Papers 19313, National Bureau of Economic Research, Inc, August 2013.

Jonathan D. Fisher, David S. Johnson, and Timothy M. Smeeding. Measuring the Trends in Inequality of Individuals and Families: Income and Consumption. American Economic Review, 103(3):184-88, May 2013.

Edward J. Green and Soo-Nam Oh. Can a "credit crunch" be efficient? Quarterly Review, (Fall):3-17, 1991. 
Weerachart T. Kilenthong and Robert M. Townsend. A Market Based Solution to Price Externalities: A Generalized Framework. NBER Working Papers 20275, National Bureau of Economic Research, Inc, July 2014.

Nobuhiro Kiyotaki. A mechanism design approach to financial frictions. September 2010.

Nobuhiro Kiyotaki and John Moore. Credit Cycles. Journal of Political Economy, 105(2):211-48, April 1997.

Evan F. Koenig. Monetary policy, financial stability, and the distribution of risk. Technical report, 2011.

Arvind Krishnamurthy. Collateral constraints and the amplification mechanism. Journal of Economic Theory, 111(2):277-292, 2003.

Bruce D. Meyer and James X. Sullivan. Consumption and Income Inequality and the Great Recession. American Economic Review, 103(3):178-83, May 2013.

Kalin Nikolov. Collateral amplification under complete markets. Journal of Economic Dynamics and Control, 45(C):80-93, 2014.

Fabrizio Perri and Joseph Steinberg. Inequality and redistribution during the great recession. Economic Policy Paper 12-1, Federal Reserve Bank of Minneapolis, 2012.

Kevin D. Sheedy. Debt and Incomplete Financial Markets: A Case for Nominal GDP Targeting. Brookings Papers on Economic Activity, 48(1 (Spring):301-373, 2014 


\section{A Proof of Proposition 1}

Proof. In period 1, upon realisaton of endowments, individual agent in receipt of endowment $y_{i}$ can buy ( + ) or offer (-) unlimited quantities of non-contingent debt $b_{i}$, each unit of which returns one unit of the consumption good in the second period. The agent's problem can be written as follows:

$$
\max _{\mathbf{c}_{i}, x_{i}, b_{i}} U\left(c_{1 i}\right)+\beta U\left(c_{2 i}\right)
$$

subject to the resource constraints

$$
\begin{gathered}
y_{i} \geq c_{1 i}+x_{i}+Q b_{i}, \quad\left(\lambda_{1 i}\right) \\
R x_{i}+b_{i}+z \geq c_{2 i} . \quad\left(\lambda_{2 i}\right)
\end{gathered}
$$

In symmetric equilibrium, the total supply of one period bonds must be equal to zero:

$$
\pi_{l} b_{l}+\pi_{h} b_{h}=0
$$

The first order necessary conditions are

$$
\begin{aligned}
c_{1 i}: & \lambda_{1 i}=U^{\prime}\left(c_{1 i}\right) \\
c_{2 i}: & \lambda_{2 i}=\beta U^{\prime}\left(c_{2 i}\right) \\
x: & \lambda_{1}=R \lambda_{2} \\
b: & Q \lambda_{1}=\lambda_{2}
\end{aligned}
$$

The agents' first order necessary conditions can be rearranged to show that agents' optimal consumption profile exhibits constant consumption over periods 1 and 2:

$$
\begin{gathered}
c_{1 h}=c_{2 h}, \\
c_{1 l}=c_{2 l} .
\end{gathered}
$$


The value of $c_{1 i}$ that satisfies $c_{1 i}=c_{2 i}$ and the individual budget constraints for the agent receiving endowment $i$ is

$$
c_{1 i}=\frac{1}{1+\beta}\left[y_{i}+\beta z\right]
$$

which is identical to the solution 3.3.

\section{B Proof of Proposition 2}

Proof. The first step in solving the planner's problem is to consider the value attainable by high endowment agents who misreport their endowment.

\section{B.1 ThE VALUE OF MISREPORTING}

A recipient of a high endowment who reports a low endowment solves the following problem

$$
V\left(c_{1 l}+y_{h}-y_{l}, c_{2 l}(z)\right)=\max _{\hat{\mathbf{c}}, x} U\left(\hat{c}_{1}\right)+\beta \mathbb{E} U\left(\hat{c}_{2}(z)\right)
$$

subject to the resource constraints

$$
\begin{aligned}
c_{1 l}+y_{h}-y_{l} \geq \hat{c}_{1}+\hat{x}, \quad\left(\hat{\lambda}_{1}\right) \\
R \hat{x}+c_{2 l}(z) \geq \hat{c}_{2}(z) \quad \forall z, \quad\left(\hat{\lambda}_{2}(z)\right)
\end{aligned}
$$

and the non-negative storage constraint,

$$
\hat{x} \geq 0 . \quad(\hat{\nu})
$$

It is clear that under any optimal consumption plan, the period 1 and period 2 resource constraints are binding $\left(\hat{\lambda}_{1}, \hat{\lambda}_{2}(z)>0\right)$. Whether or not the non-negative storage constraint is binding will depend on the allocations $c_{1 l}, c_{2 l}(z)$ and the hidden part of the agent's endowment $y_{h}-y_{l}$. 
From the period 2 budget constraints, we can see that the difference in statecontingent consumption allocations of the misreporting agents are equal to those same differences for low reporting truth-telling agents. That is,

$$
\hat{c}_{2}\left(z_{H}\right)-\hat{c}_{2}\left(z_{L}\right)=c_{2 l}\left(z_{H}\right)-c_{2 h}\left(z_{L}\right) .
$$

The agent's first order conditions are

$$
\begin{aligned}
\hat{c}_{1}: & \hat{\lambda}_{1}=U^{\prime}\left(\hat{c}_{1}\right) \\
\hat{c}_{2}(z): & \hat{\lambda}_{2}(z)=\beta U^{\prime}\left(\hat{c}_{2}(z)\right) \\
x: & \hat{\lambda}_{1}=R \mathbb{E} \hat{\lambda}_{2}(z)+\hat{\nu}
\end{aligned}
$$

and the complementary slackness condition relating to savings is

$$
\hat{x} \hat{\nu}=0 \text {. }
$$

We'll see in the next section that under constrained efficient allocations, low endowment agents' intertemporal MRS will bind with respect to the gross return to the savings technology. Consequently, misreporting agents will wish to save a strictly positive fraction of their period 1 resources. This allows us to restrict attention to cases where $\hat{x}>0, \hat{\nu}=0$. Formally, Lemma 1 describes the key results that follow:

Lemma 1. Under any allocation where low endowment agents' ex ante intertemporal marginal rates of substitution are equated to the gross return on the savings technology $\left(\frac{U^{\prime}\left(c_{1 l}\right)}{\beta \mathbb{E}_{z} U^{\prime}\left(c_{2 l}(z)\right)}=R\right)$, it follows that

(a) any misreporting agent saves a strictly positive amount of their first period wealth, $\hat{x}>0$.

(b) Misreporting agents' ex ante intertemporal marginal rate of substitution is 
equated to the gross return on savings,

$$
\frac{U^{\prime}\left(\hat{c}_{1}\right)}{\beta \mathbb{E}_{z} U^{\prime}\left(\hat{c}_{2}(z)\right)}=R
$$

(c) Under DARA preferences, the across state marginal rate of substitution of misreporting agents is strictly greater than that of truth-telling low endowment agents,

$$
\frac{U\left(\hat{c}_{2 l}\left(z_{H}\right)\right)}{U\left(\hat{c}_{2 l}\left(z_{L}\right)\right)}>\frac{U\left(c_{2 l}\left(z_{H}\right)\right)}{U\left(c_{2 l}\left(z_{L}\right)\right)}
$$

Proof. (a) Assume that $\hat{x}=0$. In accordance with the resource constraints, $\hat{c}_{2}(z)=$ $c_{2 l}(z)$ and $\hat{c}_{1}>c_{1 l}$. Given $\left(\frac{U^{\prime}\left(c_{1 l}\right)}{\beta \mathbb{E}_{z} U^{\prime}\left(c_{2 l}(z)\right)}=R\right)$, it follows that $\left(\frac{U^{\prime}\left(\hat{c}_{1}\right)}{\beta \mathbb{E}_{z} U^{\prime}\left(\hat{c}_{2}(z)\right)}<R\right)$. By the complementary slackness condition, $\hat{\nu}>0$, which after substitution into the agent's first order necessary condition for $\hat{x}$, yields $\left(\frac{U^{\prime}\left(\hat{c}_{1}\right)}{\beta \mathbb{E}_{z} U^{\prime}\left(\hat{c}_{2}(z)\right)}>R\right)$, which contradicts the previous inequality.

(b) From part (a), optimal savings are positive, $\hat{x}>0, \hat{\nu}=0$. After substitution into the agent's first order necessary condition for $\hat{x}$ we have $\left(\frac{U^{\prime}\left(\hat{c}_{1}\right)}{\beta \mathbb{E}_{z} U^{\prime}\left(\hat{c}_{2}(z)\right)}=R\right)$.

(c) From the misreporting agent's resource constraints, we see that if $\hat{x}$ is positive, $\hat{c}_{2}(z)>c_{2 l}(z)$. Combining this with Equation B.1 and the assumption of DARA preferences completes the proof.

As we'll see, the inequality described in Lemma 1 part (c) creates an opportunity for the planner to implement some insurance against idiosyncratic risks. Specifically, business cycle risk insurance plans that are desirable to low wealth individuals are undesirable to high endowment individuals, who have greater tolerance for business cycle risk. Constrained efficient mechanisms can use this information to elicit truth-telling from high endowment agents even when revelation of a high endowment motivates a transfer of wealth to low endowment agents.

Solving the planner's problem will require the use of the envelope theorem. We denote as follows the partial derivatives of the misreporting agents' value functions 
with respect to the low endowment agents' consumption allocations:

$$
\begin{gathered}
V_{1}=\frac{\partial V}{\partial c_{1 l}}=U^{\prime}\left(\hat{c}_{1}\right), \\
V_{2 z}=\frac{\partial V}{\partial c_{2 l}(z)}=\beta P(z) U^{\prime}\left(\hat{c}_{2}(z)\right) .
\end{gathered}
$$

\section{B.2 THE PLANNER'S FIRST ORDER NECESSARY CONDITIONS}

The planner's first order necessary conditions are described by the following:

$$
\begin{aligned}
c_{1 l}: & 0=\pi_{l} U^{\prime}\left(c_{1 l}\right)-\pi_{l} \lambda_{1}-\mu V_{1}\left(c_{1 l}+y_{h}-y_{l}, c_{2 l}(z)\right) \\
c_{1 h}: & 0=\pi_{h} U^{\prime}\left(c_{1 h}\right)-\pi_{h} \lambda_{1}+\mu U^{\prime}\left(c_{1 h}\right) \\
x: & 0=\lambda_{1}-R \mathbb{E} \lambda_{2}(z) \\
c_{2 l}(z): & 0=P(z) \pi_{l} \beta U^{\prime}\left(c_{2 l}(z)\right)-P(z) \pi_{1} \lambda_{2}(z)-\mu V_{2 z}\left(c_{1 l}+y_{h}-y_{l}, c_{2 l}(z)\right) \\
c_{2 h}(z): & 0=P(z) \pi_{h} \beta U^{\prime}\left(c_{2 h}(z)\right)-P(z) \pi_{h} \lambda_{2}(z)+\mu \beta P(z) U^{\prime}\left(c_{2 h}(z)\right)
\end{aligned}
$$

Eliminating $\mu$ from the planner's first order conditions with respect to the consumption allocations of high endowment individuals yields

$$
\frac{U^{\prime}\left(c_{1 h}\right)}{\lambda_{1}}=\frac{\beta U^{\prime}\left(c_{2 h}(z)\right)}{\lambda_{2}(z)}
$$

Which ensures first that high endowment agents receive business cycle risk consumption insurance commensurate with the planner's marginal value of second period wealth,

$$
\frac{U^{\prime}\left(c_{2 h}\left(z_{H}\right)\right)}{U^{\prime}\left(c_{2 h}\left(z_{L}\right)\right)}=\frac{\lambda_{2}\left(z_{H}\right)}{\lambda_{2}\left(z_{L}\right)}
$$

and second, when combined with the first order condition for aggregate savings $x$, that the high endowment agents' intertemporal marginal rates of substitution equate to the intertemporal marginal rate of transformation specified by the storage 
technology, $R$,

$$
\frac{\mathbb{E}_{z} \beta U^{\prime}\left(c_{2 h}(z)\right)}{U^{\prime}\left(c_{1 h}\right)}=\frac{1}{R}
$$

Turning to the low endowment households, eliminating $\mu$ from the first order conditions for their consumption allocations yields

$$
\frac{U^{\prime}\left(c_{1 l}\right)-\lambda_{1}}{V_{1}\left(c_{1 l}+y_{h}-y_{l}, c_{2 l}(z)\right)}=\frac{U^{\prime}\left(c_{2 l}(z)\right)-\lambda_{2}(z)}{V_{2 z}\left(c_{1 l}+y_{h}-y_{l}, c_{2 l}(z)\right) / P(z)} \text {. }
$$

From here we proceed as follows: First, we assume that equations B.2 and B.3 hold. We then verify that the ex ante intertemporal marginal rate of substitution equates to the gross return to the storage technology, $\frac{\mathbb{E}_{z} \beta U^{\prime}\left(c_{2 l}(z)\right)}{U^{\prime}\left(c_{1 l}\right)}=\frac{1}{R}$. If true, then by Lemma 1, equations B.2 and B.3 must hold.

Let equations B.2 and B.3 hold. Substituting (B.2) and (B.3) into (B.5) yields

$$
\frac{\mathbb{E}_{z} \beta U^{\prime}\left(c_{2 l}(z)\right)}{U^{\prime}\left(c_{1 l}\right)}=\frac{1}{R}
$$

and

$$
\frac{U^{\prime}\left(c_{2 l}\left(z_{H}\right)\right)}{U^{\prime}\left(c_{2 l}\left(z_{L}\right)\right)}>\frac{\lambda_{2}\left(z_{H}\right)}{\lambda_{2}\left(z_{L}\right)}
$$

Equation B.6 verifies that (B.2) and (B.3) hold by Lemma 1. Equation B.7 when combined with (B.4) shows that low endowment agents are protected from business cycle risk $(z)$, to such an extent that their second period marginal utility is less sensitive to business cycle risk than that of high endowment agents:

$$
\frac{U^{\prime}\left(c_{2 l}\left(z_{H}\right)\right)}{U^{\prime}\left(c_{2 l}\left(z_{L}\right)\right)}>\frac{U^{\prime}\left(c_{2 h}\left(z_{H}\right)\right)}{U^{\prime}\left(c_{2 h}\left(z_{L}\right)\right)}
$$




\section{Proof of Proposition 3}

Proof. Consider a mechanism that replicates the consumption allocations that are identical to those enjoyed by agents under the competitive equilibrium with noncontingent debt. Non-contingent debt does not allow for transfers of wealth contingent on the common shock $z$. Given this, and the fact that the first order conditions of the individual agents under competitive trade with non-contingent debt result in the gross interest rate being equated to the gross return to hidden savings $(1 / Q=R)$, solving the value function of misreporting agents yields the following:

$$
\begin{gathered}
V_{1}\left(c_{1 l}+y_{h}-y_{l}, c_{2 l}(z)\right)=U^{\prime}\left(c_{1 h}\right) \\
V_{2 z}\left(c_{1 l}+y_{h}-y_{l}, c_{2 l}(z)\right)=\beta P(z) U^{\prime}\left(c_{2 h}(z)\right) .
\end{gathered}
$$

Substituting these solutions into the planner's first order necessary conditions, we obtain the following:

$$
\begin{gathered}
\mu=\pi_{l}\left[\frac{U^{\prime}\left(c_{1 l}\right)-\lambda_{1}}{U^{\prime}\left(c_{1 h}\right)}\right]=\pi_{h}\left[\frac{\lambda_{1}-U^{\prime}\left(c_{1 h}\right)}{U^{\prime}\left(c_{1 h}\right)}\right] \\
\mu=\pi_{l}\left[\frac{\beta U^{\prime}\left(c_{2 l}(z)\right)-\lambda_{2}(z)}{\beta U^{\prime}\left(c_{2 h}(z)\right)}\right]=\pi_{h}\left[\frac{\lambda_{2}(z)-\beta U^{\prime}\left(c_{2 h}(z)\right)}{\beta U^{\prime}\left(c_{2 h}(z)\right)}\right] \quad \forall z .
\end{gathered}
$$

These conditions can be rearranged to obtain

$$
\begin{gathered}
\frac{\lambda_{1}}{U^{\prime}\left(c_{1 h}\right)}-\frac{\lambda_{2}(z)}{\beta U^{\prime}\left(c_{2 h}(z)\right)}=0 \\
\frac{U^{\prime}\left(c_{1 l}\right)}{U^{\prime}\left(c_{1 h}\right)}=\frac{U^{\prime}\left(c_{2 l}\left(z_{H}\right)\right)}{U^{\prime}\left(c_{2 h}\left(z_{H}\right)\right)}=\frac{U^{\prime}\left(c_{2 l}\left(z_{L}\right)\right)}{U^{\prime}\left(c_{2 h}\left(z_{L}\right)\right)} .
\end{gathered}
$$

As non-contingent debt does not allow transfers between agents contingent on $z$, the individual agents' budget constraints specify that the absolute difference in con- 
sumption across the common shock $(\mathrm{z})$ is equated across individual agents:

$$
c_{2 l}\left(z_{H}\right)-c_{2 l}\left(z_{L}\right)=c_{2 h}\left(z_{H}\right)-c_{2 h}\left(z_{L}\right) \text {. }
$$

But, as non-contingent debt also does not allow transfers of wealth across agents, the consumption smoothing by individual agents specified by their individual first order necessary conditions means that

$$
c_{2 l}(z)<c_{2 h}(z) \quad \forall z
$$

Under DARA preferences, it can be shown that $U^{\prime \prime \prime}(c)>0$. It follows that under the competitive equilibrium under non-contingent debt contracts,

$$
\frac{U^{\prime}\left(c_{2 l}\left(z_{H}\right)\right)}{U^{\prime}\left(c_{2 l}\left(z_{L}\right)\right)}<\frac{U^{\prime}\left(c_{2 h}\left(z_{H}\right)\right)}{U^{\prime}\left(c_{2 h}\left(z_{L}\right)\right)} .
$$

